\title{
SEROTONERGIC Pontomedullary Neurons Are Not Activated by Antinociceptive Stimulation in the Periaqueductal Gray
}

\author{
Keming Gao, Yoo-Hang Hugh Kim, and Peggy Mason \\ Department of Pharmacological and Physiological Sciences and the Committee on Neurobiology, University of Chicago, \\ Chicago, Illinois 60637
}

\begin{abstract}
The antinociceptive and cardiovascular effects of midbrain periaqueductal gray (PAG) stimulation are mediated through a relay in the pontomedullary raphe magnus (RM) and adjacent nucleus reticularis magnocellularis (NRMC). To test whether the neurons important in mediating PAG-evoked effects are SEROTONERGIC, the responses of pontomedullary SEROTONERGIC-LIKE cells to PAG stimulation were tested. SEROTONERGIC-LIKE neurons $(n=21)$ were recorded extracellularly in halothane-anesthetized Sprague Dawley rats. Serotonergic-like neurons were distinguished by their slow and steady background discharge. Two neurons that were physiologically characterized as SEROTONERGIC-LIKE were intracellularly labeled and processed for serotonin immunoreactivity; both cells tested contained immunoreactive serotonin. Train stimulation of sites within the midbrain PAG, at intensities of $\leq 50 \mu \mathrm{A}$, sup-
\end{abstract}

pressed the tail withdrawal from noxious heat and evoked changes in blood pressure and heart rate. No SEROTONERGIC-LIKE cells were activated by single-pulse or short-train (two to five pulses) stimulation of the PAG at antinociceptive intensities. In most cases, SEROTONERGIC-LIKE cells were unaffected by long-train stimulation (5-6 sec) of the PAG, which produced antinociception and cardiovascular changes. In contrast, $>50 \%$ of the cells in two nonserotonergic-like cell classes were activated at short latency by such PAG stimulation. In conclusion, monosynaptic excitation of SEROTONERGIC cells in RM/NRMC is unlikely to be necessary for the nociceptive and autonomic modulatory effects of PAG stimulation.

Key words: raphe magnus; serotonin; monoamine; pain modulation; autonomic modulation; antinociception
The antinociceptive effects of periaqueductal gray (PAG) stimulation are mediated at least in part by the activation of neurons in the raphe magnus (RM) and surrounding pontomedullary reticular nuclei, including nucleus reticularis magnocellularis (NRMC) (Behbehani and Fields, 1979; Sandkuhler and Gebhart, 1984; Urban and Smith, 1994). PAG cells, including cells containing excitatory amino acid transmitters, project strongly to the RM and NRMC (Beitz et al., 1983; Basbaum and Fields, 1984; Wiklund et al., 1988; Li et al., 1993; Cameron et al., 1995). Both the PAGevoked activation of RM neurons and PAG-evoked antinociception are blocked by NMDA and AMPA receptor antagonists, evidence that fast glutamatergic synapses within the RM mediate the antinociceptive effects of PAG stimulation on RM cells (Aimone and Gebhart, 1986; Wiklund et al., 1988; van Praag and Frenk, 1990). Because the RM and NRMC contain SEROTONERGIC neurons that are the major source of serotonin in the dorsal horn (Dahlstrom and Fuxe, 1964; Oliveras et al., 1977), it is commonly hypothesized that the antinociceptive effects of PAG stimulation are relayed by RM and NRMC SEROTONERGIC cells (Kandel et al., 1991). In support of this idea, spinally projecting SEROTONERGIC cells receive axodendritic synapses from degenerating terminals after PAG lesions (Lakos and Basbaum, 1988). Serotonin receptor antagonists attenuate the antinociceptive effects of PAG stimulation on dorsal horn cells and nocifensive withdrawals (Yaksh et

Received Dec. 9, 1996; revised Jan. 22, 1997; accepted Feb. 11, 1997.

This research was supported by the Brain Research Foundation and National Institutes of Health Grant NS33984. We thank David O. Chen for technical assistance, Cynthia Leung for comments on this manuscript, and Drs. R. A. McCrea, J. M. Goldberg, and D. L. Hammond for helpful conversations.

Correspondence should be addressed to Peggy Mason, Department of Pharmacological and Physiological Sciences, University of Chicago, MC 0926, 947 East 58th Street, Chicago, IL 60637.

Copyright (C) 1997 Society for Neuroscience $\quad 0270-6474 / 97 / 173285-08 \$ 05.00 / 0$ al., 1976; Carstens et al., 1981; Yezierski et al., 1982; Paul and Phillips, 1986; Peng et al., 1996). Neurotoxic depletion of serotonin also results in the attenuation of PAG-evoked inhibition of dorsal horn cells (Carstens et al., 1981).

In addition to having nociceptive modulatory effects, PAG stimulation also evokes changes in autonomic function, including cardiovascular tone. Stimulation within the ventrolateral PAG evokes hypotension and bradycardia and facilitates the vagalmediated baroreflex, effects that are blocked by lesions of RM and NRMC (Inui et al., 1994, 1995). It has been postulated that the RM and NRMC cells that mediate the parasympathetic modulation evoked by PAG stimulation are SEROTONERGIC. In support of this idea, serotonin-containing terminals synapse on preganglionic parasympathetic cells that are located in nucleus ambiguus and innervate the heart in the rat (Izzo et al., 1993). Microinjection of serotonin into nucleus ambiguus mimics the effect of PAG stimulation on heart rate (Izzo et al., 1988).

Stimulation of the dorsal PAG evokes an increase in blood pressure and heart rate (Lovick, 1991), effects that may be mediated by the action of SEROTONERGIC RM and NRMC cells on preganglionic sympathetic neurons in the thoracic cord (Jensen et al., 1995). Within the thoracic spinal cord, serotonin depolarizes preganglionic sympathetic neurons (Coote et al., 1981; Yoshimura and Nishi, 1982; Kadzielawa, 1983; Inokuchi et al., 1990), and serotonin receptor antagonists or serotonin depletion block the pressor response evoked by raphe stimulation (McCall, 1984). The influence of SEROTONERGIC RM and NRMC cells on sympathetic tone may be mediated either directly through RM and NRMC projections to the intermediolateral cell column (Poulat et al., 1992; Zagon and Smith, 1993) or indirectly through projections to the rostral ventrolateral medulla (RVLM), a region that 

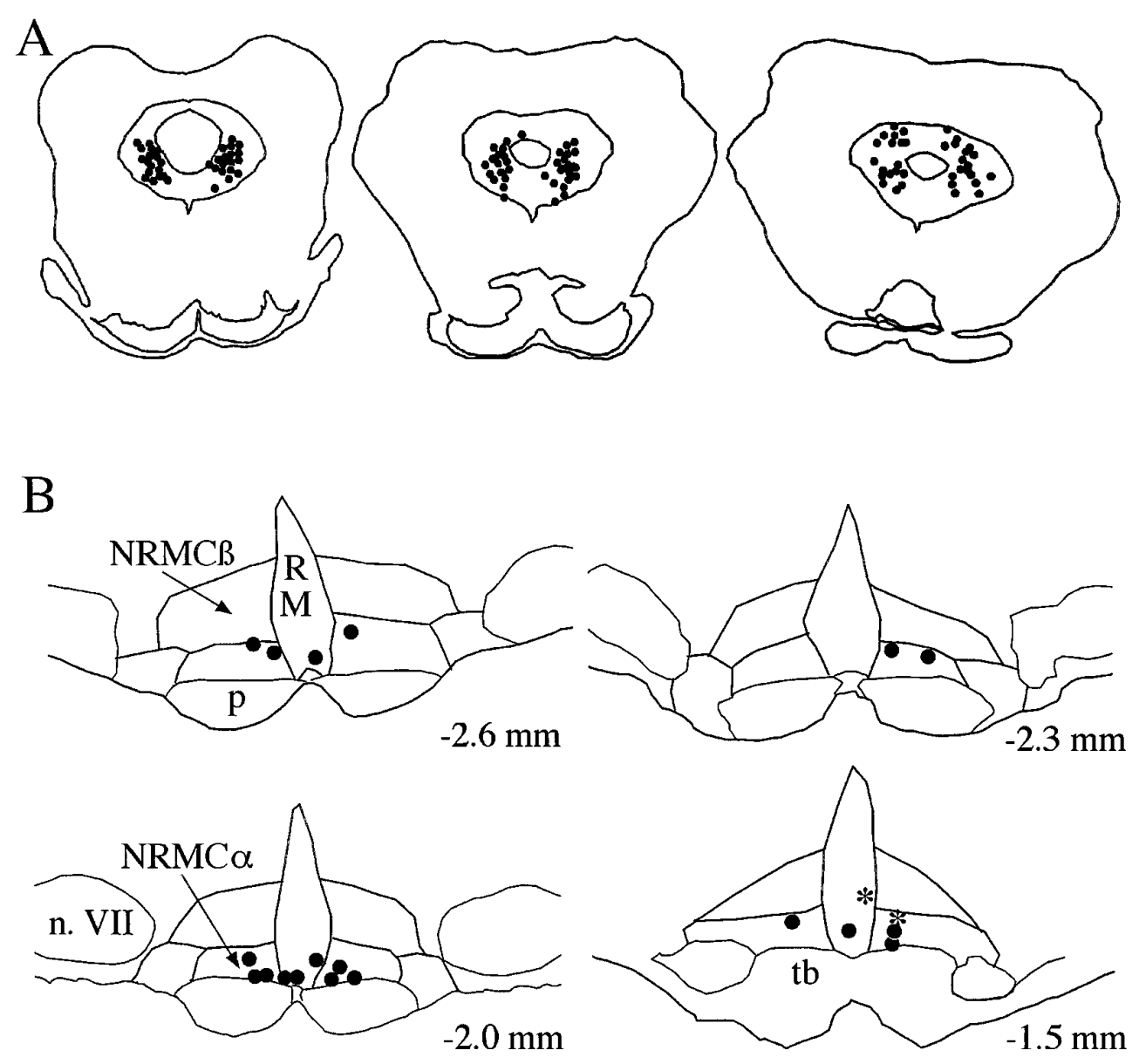
sites. $A$, PAG stimulation sites. The most caudal section is shown on the left and the most rostral on the right. $B$, Pontomedullary recording sites for SEROTONERGIC (asterisks) and SEROTONERGIC-LIKE (filled circles) cells. The rostrocaudal location of each section is shown on the bottom right. n. VII, Facial nucleus; $N R M C \alpha$, nucleus reticularis magnocellularis pars $\alpha ; N R M C \beta$, nucleus reticularis magnocellularis pars $\beta ; p$, pyramid; $R M$, raphe magnus; $t b$, trapezoid body.
Figure 1. Stimulation and recording

also contains bulbospinal SEROTONERGIC cells (Mason and Fields, 1989; Schenberg and Lovick, 1995) .

If SEROTONERGIC cells mediate the nociceptive and/or cardiovascular modulatory effects of PAG stimulation, then PAG stimulation would be expected to activate RM and NRMC SEROTONERGIC cells. Although previous work has demonstrated that long-train $(10 \mathrm{sec})$ stimulation of the PAG excites RM/NRMC ON and ofF cells (Vanegas et al., 1984), two types of nonserotonergic cells in the rat (Vanegas et al., 1984; Potrebic et al., 1994; Mason, 1997), the response of RM/NRMC SEROTONERGIC cells has not been tested directly. Recently an electrophysiological method for identifying pontomedullary SEROTONERGIC cells in the rat has been developed (Mason, 1997), enabling a direct test of the effects of PAG stimulation on RM and NRMC SEROTONERGIC-LIKE cells.

\section{MATERIALS AND METHODS}

Experimental protocol. Male Sprague Dawley rats (Sasco, Madison, WI, or Harlan, Indianapolis, IN) were used. Rats were pretreated with atropine sulfate $(40 \mu \mathrm{g}$ in $0.1 \mathrm{ml}$, s.c.) $10 \mathrm{~min}$ before anesthetic induction with halothane. A Y-tube was inserted into the trachea, and anesthesia was maintained with $2 \%$ halothane in oxygen during surgery. A posterior craniotomy was made overlying the cerebellum, and the exposed dura was cut. Electrodes were inserted bilaterally into the thorax to record the electrocardiogram and into the paraspinous muscles to record the electromyographic activity during tail withdrawal. In some animals, an arterial catheter was inserted into the femoral artery to record blood pressure. Core body temperature was maintained at $36-38^{\circ} \mathrm{C}$. After surgical preparation, the halothane concentration was reduced to $1 \%$, and the animal was allowed to equilibrate at this concentration for $30 \mathrm{~min}$ before recording.

Six stainless steel microelectrodes tip-plated with platinum were used to stimulate three regions of the PAG [anterior (A), 0.3-3.3 mm from interaural zero; lateral (L), 0-2.0 mm; ventral (V), 5.0-7.0 mm from cerebral surface] bilaterally. The array of six monopolar stimulating electrodes was inserted at an angle of $30^{\circ}$ rostral to the frontal plane. To ensure correct placement of the stimulation electrodes, suppression of the tail flick (TF) reflex evoked by noxious heat was confirmed using train stimulation of the PAG ( $\leq 50 \mu \mathrm{A}, 200 \mu \mathrm{sec}$ pulses, 5-6 sec trains, $300 \mathrm{~Hz})$ for a period 1-2 sec longer than the baseline TF latency (2-4 sec) and beginning $\leq 1 \mathrm{sec}$ before the tail heat stimulus.

A recording microelectrode was inserted into the region of the RM/ NRMC [posterior $(\mathrm{P}),-1.5$ to $-2.6 \mathrm{~mm} ; \mathrm{L}, 0.0-1.0 \mathrm{~mm} ; \mathrm{V}, 9.0-10.5 \mathrm{~mm}$ from the cerebellar surface]. Both glass micropipettes and stainless steel electrodes were used for recording. Stainless steel microelectrodes were solution of $0.1 \mathrm{M}$ Tris buffer, $\mathrm{pH} 7.4$, and $0.5 \mathrm{M} \mathrm{KCl}$ and broken to a final tip resistance of $0.5-5.0 \mathrm{M} \Omega$ or with $2 \%$ Neurobiotin in the above solution and used with a tip resistance of $40-70 \mathrm{M} \Omega$. Cells were isolated and discriminated using a slope-triggered two-point discriminator (Bak Electronics, Germantown, MD).

All cells were characterized as SEROTONERGIC-LIKE or nonserotonergiclike using a previously described algorithm that makes use of quantitative differences between the two populations of cells in the rate and variability of the interspike intervals recorded during background conditions (Mason, 1997). A cross-validation procedure estimated the probability of misclassification using this discriminant function to be $<10 \%$. Therefore, in the present study the background discharge of isolated cells was recorded for $5 \mathrm{~min}$, and the mean and SD of the interspike intervals was calculated from this recording. For each cell, the value of the function:

$$
y(\bar{x}, s)=146-\bar{x}+0.98 s
$$

was calculated, where $\bar{x}$ is the mean interspike interval (in milliseconds), and $s$ is the SD of the intervals (in milliseconds). Cells were classified as SEROTONERGIC-LIKE if the function value was $<0$ and as nonserotonergiclike if the function value was $>0$ (Mason, 1997). All cells were further characterized by their responses to noxious tail heat and noxious pinch of the hindpaws and tail, as described previously. tip-plated with platinum. Glass micropipettes were filled either with a 

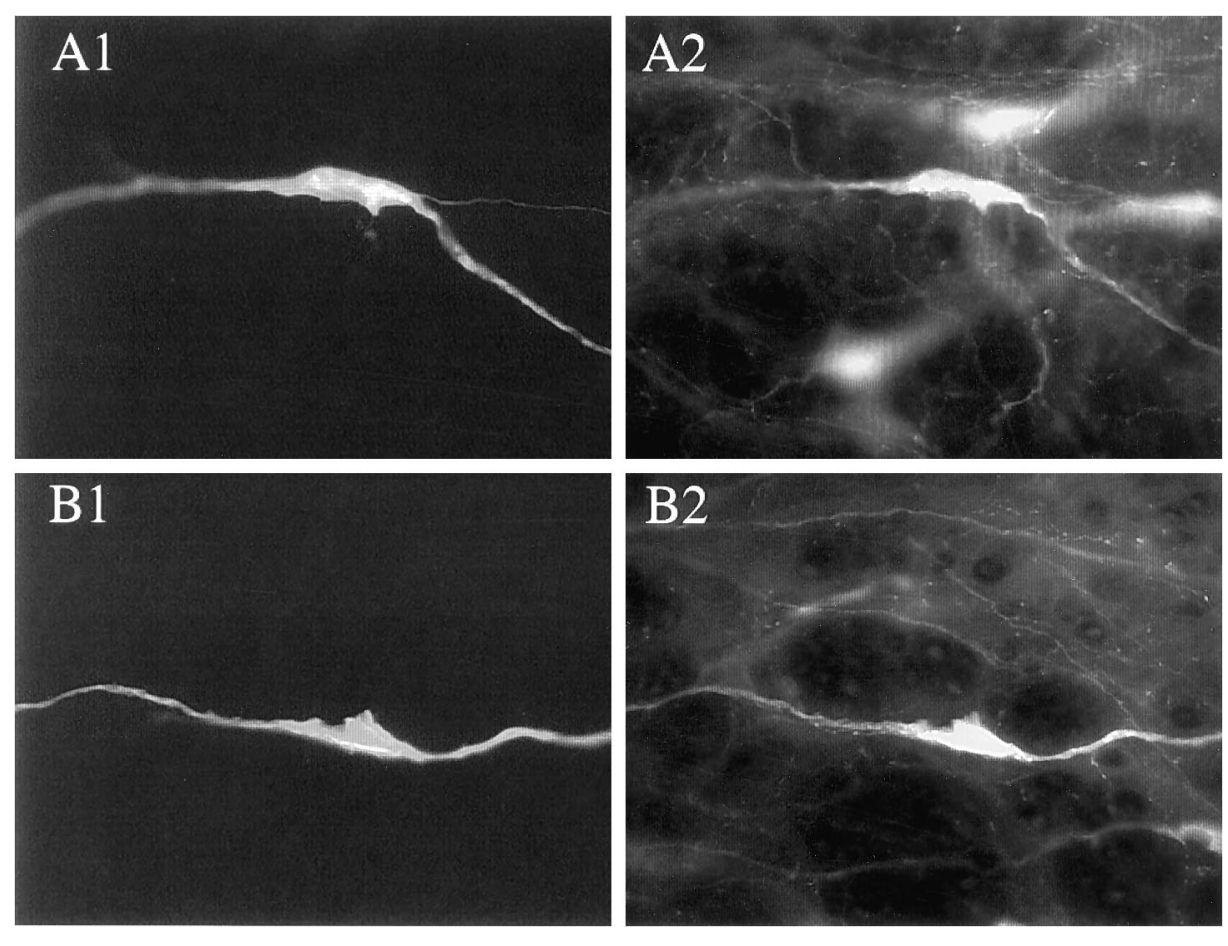

Figure 2. Photomicrographs of two SEROTONERGIC cells. $A 1, B 1$, The intracellular label of each cell is visualized with Texas Red. $A 2, B 2$, The same field is seen after processing for serotonin immunoreactivity visualized with Bodipy.
After characterization, cells were tested for their responses to PAG stimulation at all six sites in the electrode array at a current of 50-500 $\mu \mathrm{A}$ with single shocks or short trains $(300-500 \mathrm{~Hz})$ of two to six pulses. Selected cells were then tested during long trains (5-6 sec) of PAG stimulation that were effective in suppressing the TF withdrawal or in producing a cardiovascular change. To determine whether a cell responded to tail heat or long-train PAG stimulation or both, the cell discharge rate before, during, and after the stimulus was calculated for 6 sec bins. In the absence of stimulation, the variation in the number of spikes per $6 \mathrm{sec}$ bin was always $\leq 35 \%$. Therefore, cells were considered to be affected by the stimulation if their discharge rate was changed by $\geq 40 \%$.

After the recording session, the final recording site and the stimulating sites were lesioned with $20 \mathrm{nA}$ negative direct current for $4 \mathrm{~min}$. The animals were perfused with saline and $500 \mathrm{ml}$ of fixative. Coronal serial sections $(40-50 \mu \mathrm{m})$ were cut on a freezing microtome. Pontomedullary sections containing SEROTONERGIC-LIKE cells were stained for serotonin immunoreactivity as described previously (Mason, 1997).

In two cases, cells were intracellularly labeled with Neurobiotin, which was subsequently visualized with a Texas Red fluorophore. These cells were then processed for serotonin immunofluorescence using a Bodipy fluorophore, as described previously (Mason, 1997). Midbrain sections containing the stimulation sites were stained with cresyl violet.

Unless stated otherwise, all statistics are expressed as mean \pm SEM.

\section{RESULTS}

The histologically verified sites of PAG stimulation were located bilaterally in the caudal (0.3-0.7 $\mathrm{mm}$ rostral to interaural zero), middle $(1.7-2.3 \mathrm{~mm})$, and rostral $(2.7-3.3 \mathrm{~mm})$ thirds of the ventral PAG. Most stimulation sites in the caudal and middle thirds of the PAG were concentrated in the ventral half of PAG, whereas those of the rostral third of PAG were located throughout the dorsoventral range within PAG (Fig. $1 A$ ). In each experiment, train stimulation (4-6 sec, $300 \mathrm{~Hz}, 200 \mu \mathrm{sec}, \leq 50 \mu \mathrm{A})$ of two to six PAG sites was effective in suppressing the withdrawal evoked by noxious tail heat.

A total of 21 SEROTONERGIC-LIKE cells from 18 animals were recorded and analyzed. Histological sites for the recorded and analyzed cells were found to be in RM and NRMC $\alpha$, regions that contain serotonin-immunoreactive cells (Fig. $1 B$ ). In two cases, physiologically characterized SEROTONERGIC-LIKE cells were intra- cellularly labeled and tested for serotonin immunoreactivity. In both cases, the SEROTONERGIC-LIKE cells contained serotonin immunoreactivity (Fig. 2). Because there were no differences between the SEROTONERGIC-LIKE and serotonergic cells, the two groups will be discussed together below and referred to as SEROTONERGIC-LIKE.

SEROTONERGIC-LIKE cells had background discharge rates of $0.4-2.9 \mathrm{~Hz}$ (mean $1.4 \pm 0.2 \mathrm{~Hz}$ ) (Fig. 3). The mean coefficient of variation of the interspike interval was $0.52 \pm 0.03$, with a range of $0.18-0.80$. SEROTONERGIC-LIKE cells were unaffected $(n=13)$ or slightly excited $(n=8)$ by noxious tail heat and unaffected $(n=14)$ or slightly excited $(n=7)$ by noxious pinch.

Single- and double-pulse stimulation of the PAG, at intensities of up to $500 \mu \mathrm{A}$, did not alter the discharge rate of any SEROTONERGIC-LIKE cell tested $(n=21)$ (Fig. $4 A)$. Short-train (three to six pulses) stimulation of PAG, at intensities of 50-150 $\mu \mathrm{A}$, was ineffective in altering the discharge of any SEROTONERGICLIKE cell. Short-train stimulation, at a stimulation intensity of 500 $\mu \mathrm{A}$, of 24 PAG sites was tested on four SEROTONERGIC-LIKE cells. At such currents, two cells were excited by stimulation of only four PAG sites (Fig. 4B-D). The latency from the first PAG shock to peak excitation of these two RM/NRMC SEROTONERGIC-LIKE cells was $18-23 \mathrm{msec}$. The latency to the recorded response was highly variable, making it unlikely that this represents a monosynaptic connection. Furthermore, the calculated conduction velocities for a monosynaptic connection, assuming a synaptic delay of $0.5 \mathrm{msec}$, for each of the four PAG site-RM/NRMC cell pairs would be $0.3-0.4 \mathrm{~m} / \mathrm{sec}$.

During PAG-evoked suppression of the TF $(50 \mathrm{uA}, 300 \mathrm{~Hz}, 6$ $\mathrm{sec}$ ), the discharge of most SEROTONERGIC-LIKE cells did not change (Fig. 5). In two cases, there were small increases in discharge associated with the PAG train stimulation (Fig. $5 F$ ). These increases always had a latency of several seconds. During PAG-evoked changes in blood pressure, the discharge of SEROTONERGIC-LIKE cells did not change (Fig. 5B,D,F). 
Figure 3. Graph of the background discharge characteristics of recorded cells. The coefficient of variation $(\mathrm{CV})$ of the interspike interval is plotted against the mean interspike interval for a 5 min period of background discharge. A line representing the discriminant function $[y(\bar{x}$, $s)=0$ ] defines the optimal linear boundary between SEROTONERGIC and nonserotonergic cells and is illustrated on this same graph. SEROTONERGIC-LIKE (open circles) and SEROTONERGIC ( filled circles) cells are all located below the discriminant line. Nonserotonergic-like cells that respond (asterisks) or do not (plusses) respond to PAG stimulation are all located above the discriminant line. Nonserotonergic-like cells with a CV $>3.5(n=16)$ are not shown on this graph.

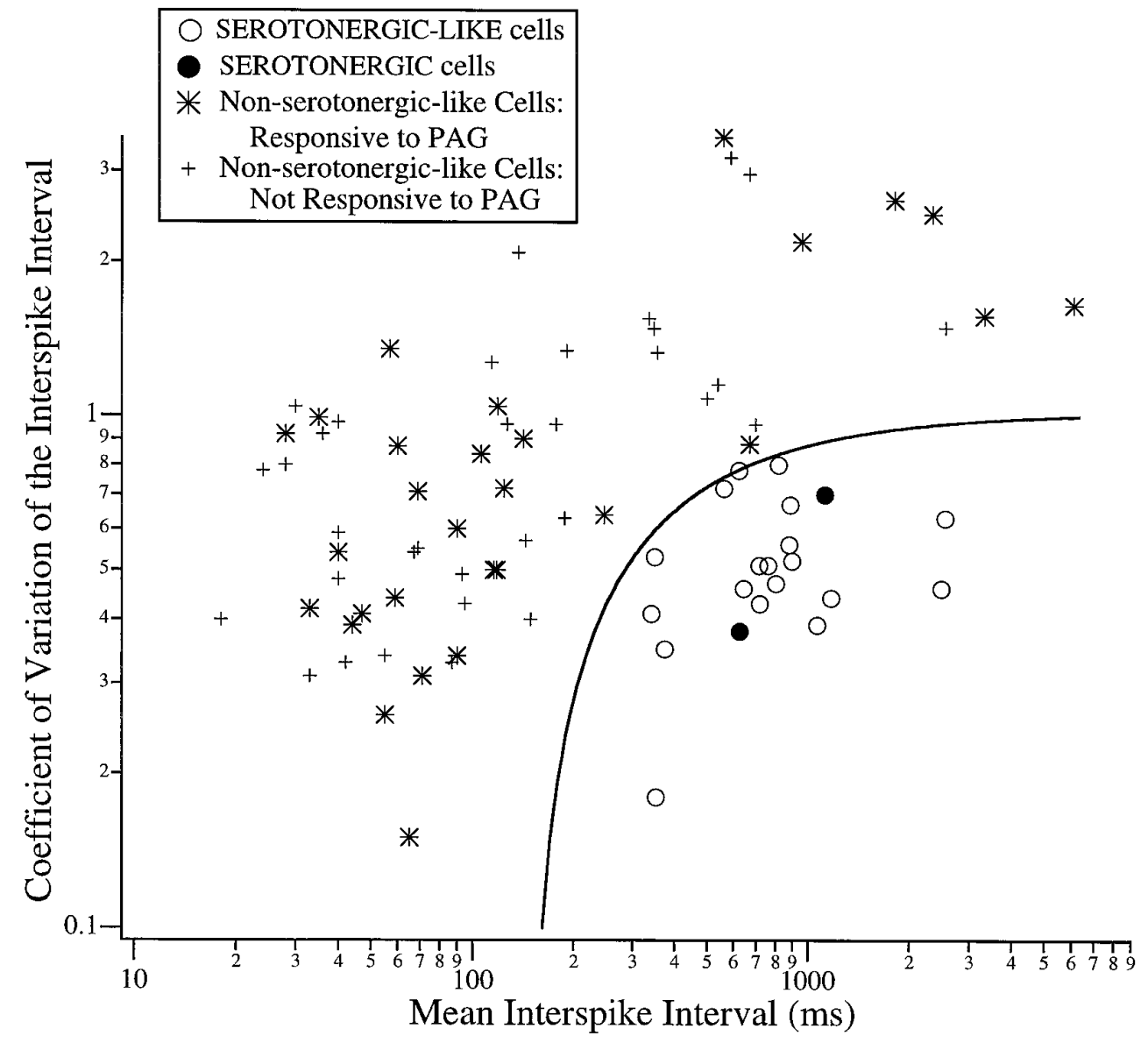

No SEROTONERGIC-LIKE cells were antidromically activated by PAG stimulation at any site.

Although the PAG stimulation was effective in evoking PAG suppression of the noxious-evoked TF, additional confirmation of the efficacy of PAG stimulation was examined by recording from nonserotonergic-like cells in RM and NRMC, which have previously been reported to respond to PAG stimulation (see introductory remarks). Nonserotonergic-like cells were recorded in the same animals as the SEROTONERGIC-LIKE cells discussed above. The background discharge of nonserotonergic-like cells was faster and/or more irregular than that of SEROTONERGIC-LIKE cells (Fig. 3). Nonserotonergiclike cells were characterized further as oN $(n=15)$, OFF $(n=$ $10)$, and NEUTRAL $(n=47)$ cells, as described previously (Leung and Mason, 1995; Mason, 1997). Single-pulse or short-train (two to six pulses) stimulation, with currents of $\leq 200 \mu \mathrm{A}$, evoked a short latency excitation in $64 \%$ of the on cells, $56 \%$ of the ofF cells, and $27 \%$ of the NEUTRAL cells. The latency for PAG excitation of nonserotonergic RM/NRMC cells varied from $<2 \mathrm{msec}$ to $>10 \mathrm{msec}$. A small proportion of on (27\%) and NEUTRAL $(15 \%)$ cells were antidromically activated by PAG stimulation at latencies of $0.8-3.5 \mathrm{msec}$.

\section{DISCUSSION}

\section{Summary}

The current study provides little evidence for a monosynaptic excitatory connection between PAG and RM/NRMC SEROTONERGIC cells. Short-train stimulation of sites located throughout the rostrocaudal extent of the midbrain PAG, at intensities that suppressed the noxious-evoked TF, failed to activate any of the 21 SEROTONERGIC-LIKE cells tested. Furthermore, PAG suppression of the TF occurred in the absence of SEROTONERGIC-LIKE cell activation. In the two cases in which PAG suppression evoked an increase in SEROTONERGIC-LIKE cell discharge, this activation was likely attributable to oligo- or polysynaptic rather than monosynaptic pathways (see below).

Two SEROTONERGIC-LIKE cells were excited at short latency by PAG train stimulation at an intensity of $500 \mu \mathrm{A}$. The latency of these excitations $(18-23 \mathrm{msec})$ is evidence that if a monosynaptic excitatory connection exists between PAG and RM/NRMC SEROTONERGIC cells, the conduction velocity would have to be very slow, $\leq 0.4 \mathrm{~m} / \mathrm{sec}$. Shah and Dostrovsky (1980) reported a mean conduction velocity of $4.1 \mathrm{~m} / \mathrm{sec}$ for PAG units that project to the $\mathrm{RM}$ in the rat; only 3 of 29 PAG units had conduction velocities in the unmyelinated range $(\leq 1 \mathrm{~m} / \mathrm{sec})$, the slowest of which conducted at $0.4 \mathrm{~m} / \mathrm{sec}$.

The activation of two SEROTONERGIC-LIKE cells by train stimulation of the PAG, reported above, is likely attributable to current spread or activation of oligosynaptic pathways or both. Responses were evoked by short-train stimulation only at intensities of $\geq 500$ $\mu \mathrm{A}$. At such high intensities, somata and myelinated fibers that are $\geq 750 \mu \mathrm{m}$ and $1.5 \mathrm{~mm}$, respectively, from the electrode are likely to be stimulated (Ranck, 1975). In response to long-train (6 sec) stimulation at intensities of $50 \mu \mathrm{A}$, two cells responded with a small increase in discharge rate that had a latency of several seconds. This long latency suggests that the response may be secondary to a gross stimulation effect (Depaulis and Bandler, 

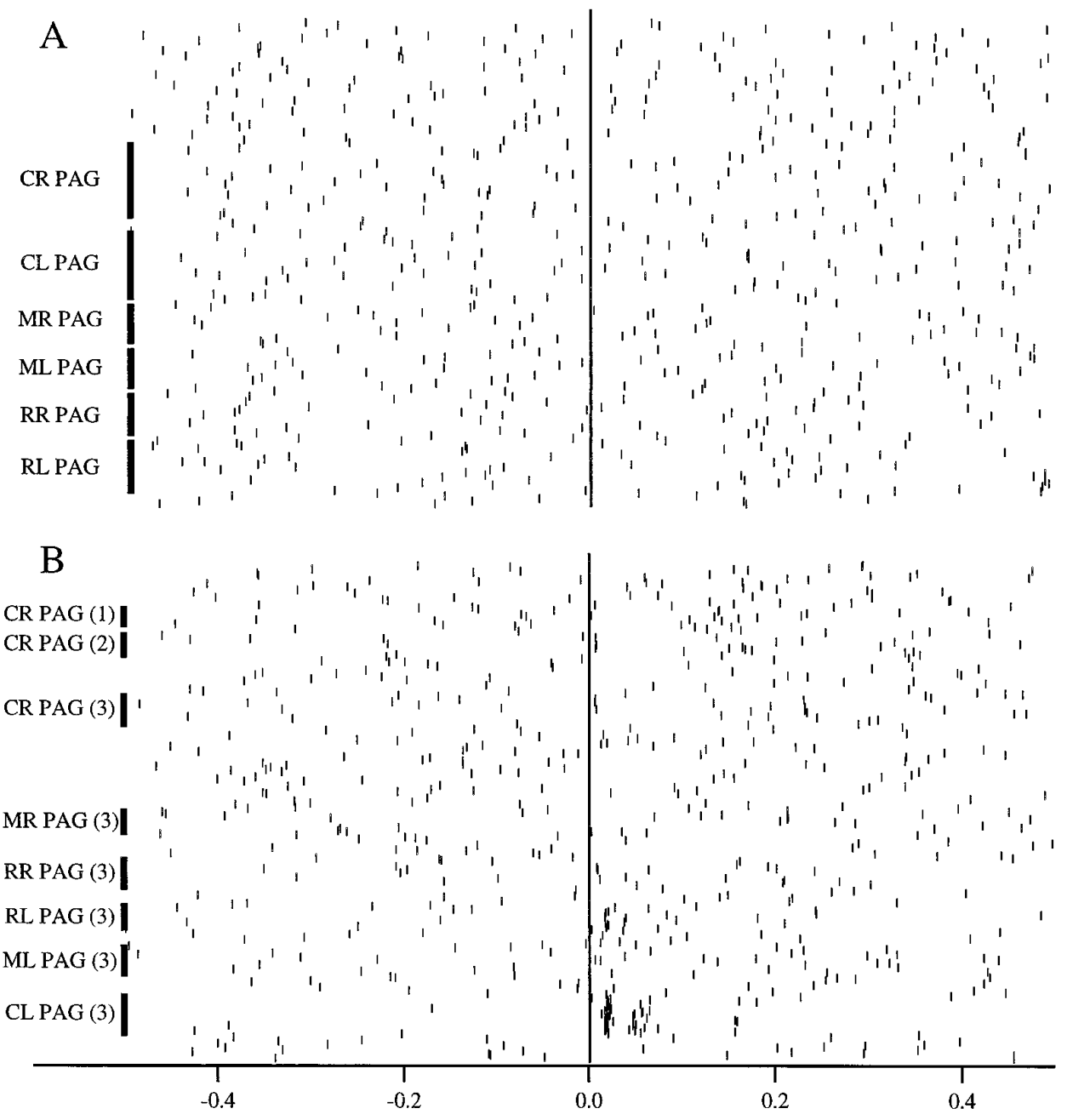

Time (s)
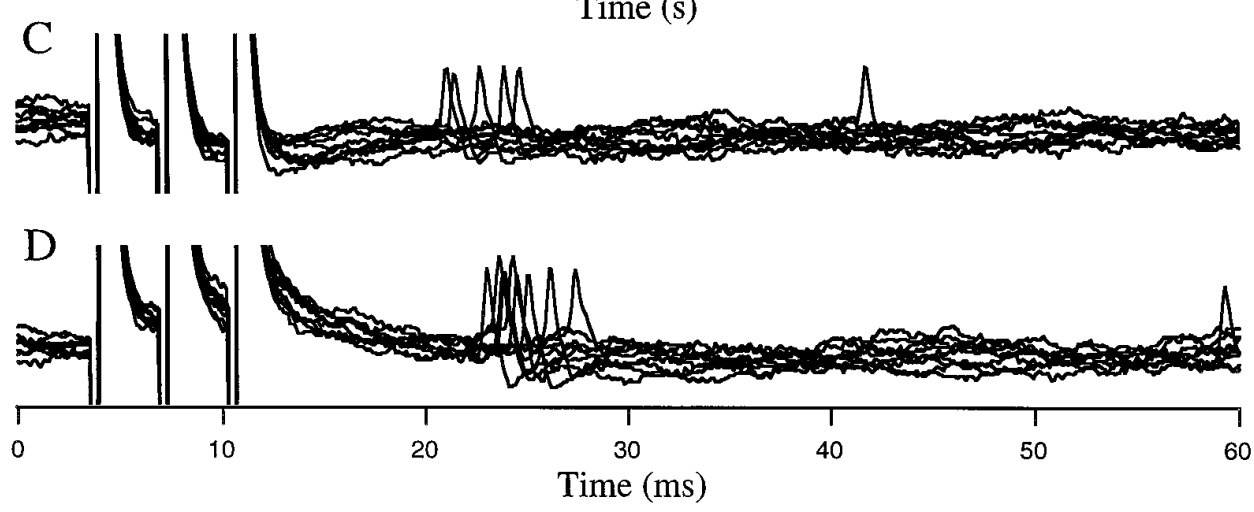

Figure 4. Responses of a SEROTONERGIC cell to PAG stimulation. $A$, A raster plot of a SEROTONERGIC-LIKE cell that does not respond to single-pulse stimulation of any PAG site tested. The top of the figure represents background activity, and the bars on the left demarcate periods of PAG stimulation (1 pulse, 200 $\mu \mathrm{sec}$ pulse, $500 \mu \mathrm{A}$; trials repeated at 1 $\mathrm{Hz}$ ). $B$, A raster plot of a SEROTONERGIC cell that responds to short-train stimulation of two of six PAG sites tested. The top of the figure represents background activity, and the bars on the left demarcate periods of PAG stimulation (1-3 pulses, $300 \mathrm{~Hz}, 200 \mu$ sec pulses, $500 \mu \mathrm{A}$; trials repeated at $1 \mathrm{~Hz}$ ). $C$, Extracellular recordings from the SEROTONERGIC cell shown in $B$ in response to rostral left PAG stimulation. Ten traces are overlaid. $D$, Extracellular recordings from the SEROTONERGIC cell shown in $B$ and $C$ in response to caudal left PAG stimulation. Ten traces are overlaid.
1991). It is less likely that these long-latency effects are attributable to monosynaptic connections.

All SEROTONERGIC-LIKE cells were characterized using a previously described algorithm developed from an analysis of more than 45 physiologically characterized, intracellularly labeled and immunocytochemically tested cells (Mason, 1997). As mentioned above, the probability of misclassification using this discriminant function is likely to be $<10 \%$. The similarity between the background discharge pattern, response to noxious stimulation, and nuclear location of the cells recorded in the current study and those of intracellularly labeled SEROTONERGIC cells allows some confidence in the use of this discriminant function on immuno- chemically untested cells. Moreover, the validity of the classification scheme was supported further by the observation that two physiologically characterized, SEROTONERGIC-LIKE cells contained serotonin immunoreactivity.

\section{Functional implications}

The current findings suggest that the fast glutamatergic input that mediates the antinociceptive effects of PAG activation (see introductory remarks) is likely to act on RM/NRMC nonserotonergic cells. This is consistent with the previous observation that intracellularly labeled RM cells that receive a monosynaptic EPSP 
A. Control Tail Heat

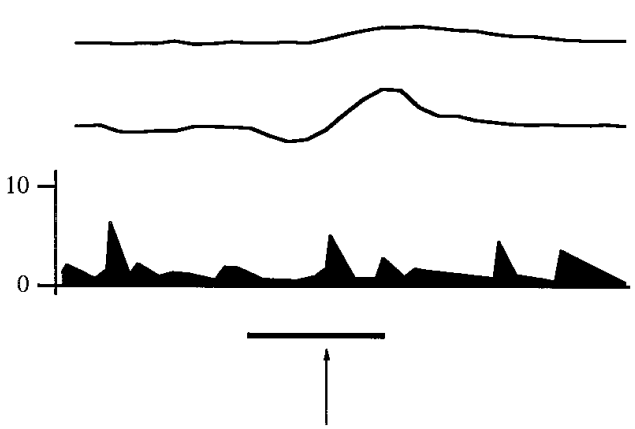

B. Rostral Right PAG Suppression a point at $10 \mathrm{~Hz}$ reflects an action potential that occurred $100 \mathrm{msec}$ after the preceding action potential; it does not reflect the occurrence of 10 action potentials within a bin. Adjacent points are joined by lines, and the graph is filled to the zero line. The middle trace represents the systemic blood pressure, and the top trace shows the instantaneous heart rate. The bar below the trace indicates where the heat stimulus was applied, and the arrow shows the time of the animal's withdrawal. $A$, Instantaneous discharge rate during a control trial of noxious tail heat. $B$, Discharge during suppression of the noxious heat-evoked TF by stimulation in the rostral right PAG $(300 \mathrm{~Hz}, 200 \mu \mathrm{sec}$, $50 \mu \mathrm{A}$; dashed line under graph). $C$, Discharge during a control trial of noxious tail heat obtained $3 \mathrm{~min}$ after the suppression test shown in $B$. D, Discharge during suppression of the noxious heat (solid bar under graph)-evoked TF by stimulation in the rostral left PAG $(300 \mathrm{~Hz}, 200 \mu \mathrm{sec}, 50$ $\mu \mathrm{A}$; dashed line under graph). E, Discharge during a control trial of noxious tail heat obtained 3 min after the suppression test shown in $D . F$, Discharge during suppression of the noxious heat (solid bar under graph)-evoked TF by stimulation in the caudal left PAG $(300 \mathrm{~Hz}, 200 \mu \mathrm{sec}, 50$ $\mu \mathrm{A}$; dashed line under graph). $G$, Discharge during a recovery trial of noxious tail heat (solid bar under graph) obtained 3 min after the suppression test shown in $F$. The scale bar on the left of each trace represents the instantaneous discharge frequency; the scale bar on the right of each trace represents $0-100$ for the blood pressure and 0-400 for the heart rate. $H$, This serotonergic cell was intracellularly labeled. The somatodendritic arbor is illustrated. The arrow points at the soma.
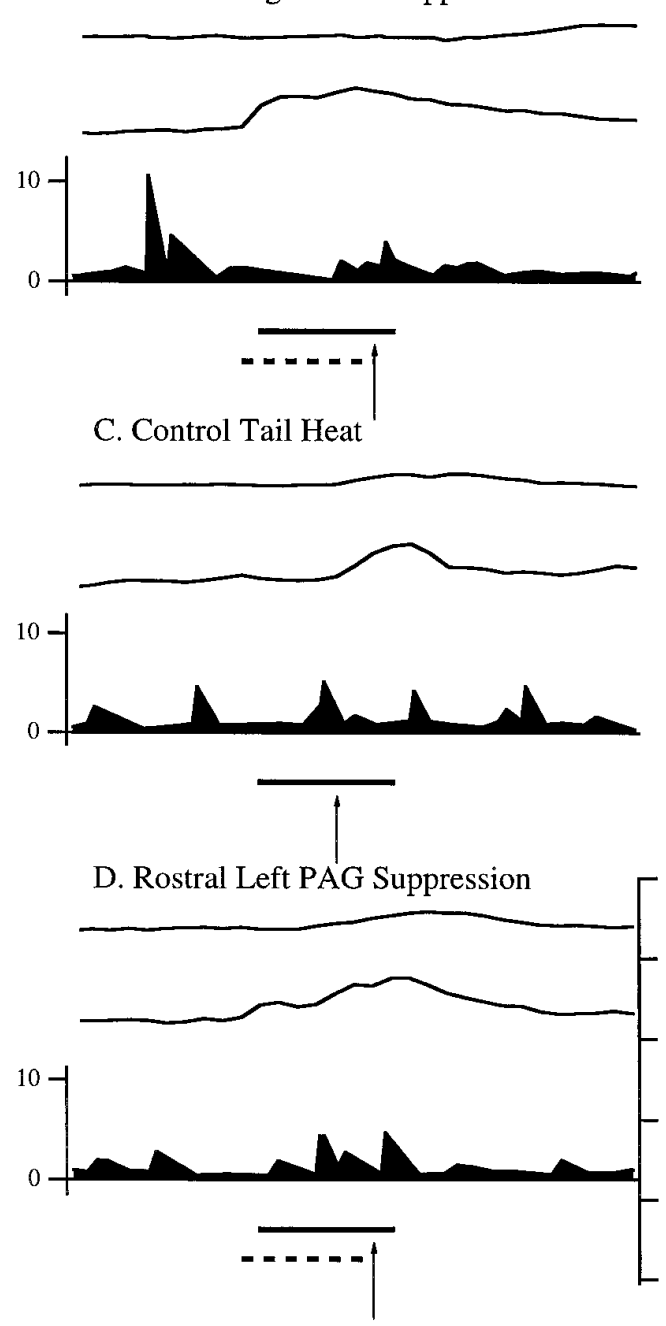

E. Control Tail Heat

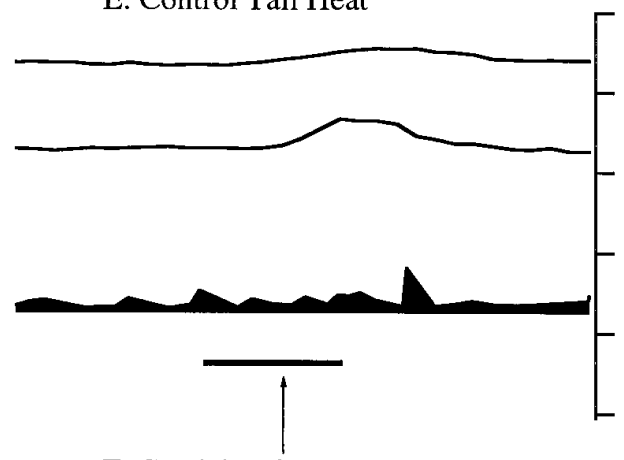

F. Caudal Left PAG Suppression
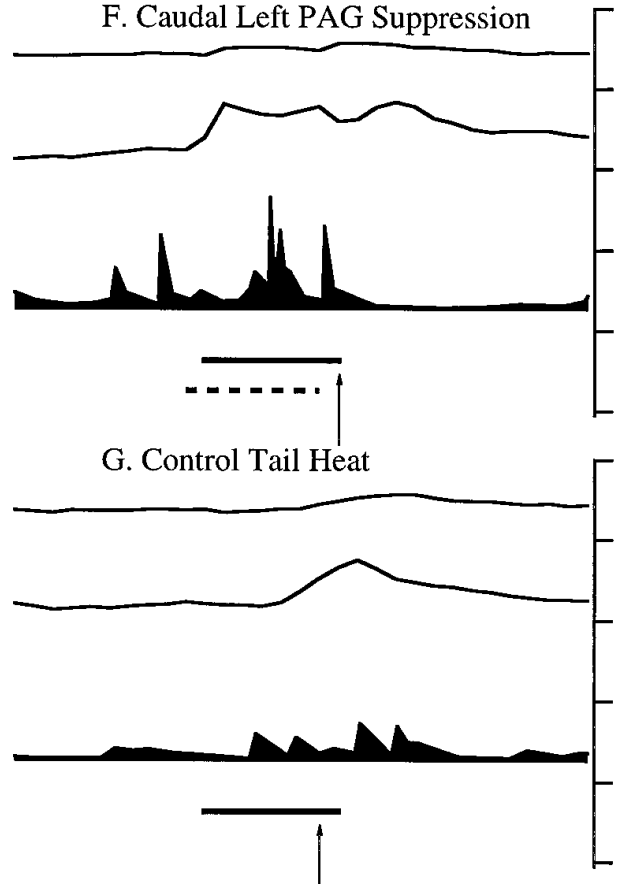

H. Cell Location

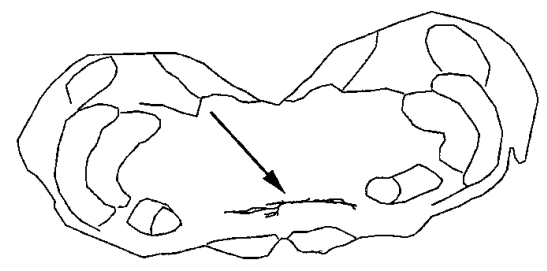

from PAG stimulation do not contain serotonin immunoreactivity in the cat (Mason et al., 1988).

In light of the anatomical evidence that PAG cells project to serotonin-containing neurons in RM, the current finding that pontomedullary SEROTONERGIC-LIKE cells do not respond physiologically to PAG stimulation is puzzling. It is possible that PAGderived synaptic input to SEROTONERGIC RM and NRMC cells is not of sufficient strength to change the discharge rate recorded extracellularly. It is also possible that PAG stimulation inhibits SEROTONERGIC cells; any inhibition lasting less than the mean interspike interval (i.e., 300-2000 msec) would be difficult to detect in the present study. Finally, SEROTONERGIC cells in RM and
NRMC are a heterogeneous population with regard to physiology, morphology, and neurochemistry (Bowker et al., 1982; Mason, 1997; K. Gao and P. Mason, unpublished observations). It is possible therefore that a subset of the SEROTONERGIC cell population in RM and NRMC is monosynaptically excited by PAG activation but was not recorded in the present study.

The lack of a strong physiological input from PAG to pontomedullary SEROTONERGIC-LIKE cells is also puzzling because of the large body of evidence that the antinociceptive and cardiovascular modulatory effects of PAG stimulation are mediated, at least in part, by the spinal release of serotonin. Pontomedullary SEROTONERGIC cells are the primary, if not the only, source of serotonin 
in the spinal cord (Dahlstrom and Fuxe, 1964; Oliveras et al., 1977). As described in the introductory remarks, a number of studies have demonstrated that the local application of serotonin receptor antagonists attenuate the antinociceptive and cardiovascular modulatory effects of PAG stimulation. A tonic release of serotonin within the spinal cord, as suggested by a number of studies (Rivot et al., 1987; Duggan, 1992; Peng et al., 1996), is the most parsimonious explanation for the paradox of SEROTONERGIC cells not being activated by PAG stimulation, whereas PAG stimulation evokes serotonin-sensitive modulatory affects on nociception and cardiovascular tone. In support of this idea, local application of serotonin antagonists alters the background discharge of dorsal horn and preganglionic sympathetic cells (Kadzielawa, 1983; Rivot et al., 1987; Peng et al., 1996). Local application of serotonin or serotonin agonists excites preganglionic sympathetic neurons and has primarily inhibitory effects on the nociceptive responses of dorsal horn cells (el Yassir et al., 1988; Bras et al., 1989). Serotonin antagonists facilitate nociceptive transmission (Rivot et al., 1987; Peng et al., 1996) and inhibit sympathetic activity (Huangfu et al., 1994) in the anesthetized rat. SEROTONERGIC cells discharge tonically (Mason, 1997), steadily releasing serotonin within the dorsal horn and the intermediolateral cell column in this same condition. During PAG activation, nonserotonergic cells in RM, NRMC, and RVLM are activated (Hilton and Smith, 1984; Vanegas et al., 1984; Mason et al., 1988; Gao and Li, 1993), presumably releasing nonserotonergic transmitters and neuropeptide modulators within both the dorsal horn and the intermediolateral cell column. Serotonin may then modulate the electrophysiological effects of neuropeptides and amino acid neurotransmitters released from bulbospinal terminals (Murase et al., 1990). During PAG stimulation, local application of serotonin antagonists would then attenuate the serotonin-mediated modulation of nonserotonergic neurotransmitters and neuromodulators. In this way, the effects of PAG stimulation on nociceptive transmission and cardiovascular control would be sensitive to serotonin antagonists (McCall, 1984; Peng et al., 1996).

\section{REFERENCES}

Aimone LD, Gebhart GF (1986) Stimulation-produced spinal inhibition from the midbrain in the rat is mediated by an excitatory amino acid neurotransmitter in the medial medulla. J Neurosci 6:1803-1813.

Basbaum AI, Fields HL (1984) Endogenous pain control systems: brainstem spinal pathways and endorphin circuitry. Annu Rev Neurosci 7:309-338.

Behbehani MM, Fields HL (1979) Evidence that an excitatory connection between the periaqueductal gray and nucleus raphe magnus mediates stimulation produced analgesia. Brain Res 170:85-93.

Beitz AJ, Shepard RD, Wells WE (1983) The periaqueductal gray-raphe magnus projection contains somatostatin, neurotensin and serotonin but not cholecystokinin. Brain Res 261:132-137.

Bowker RM, Westlund KN, Sullivan MC, Wilber JF, Coulter JD (1982) Transmitters of the raphe-spinal complex: immunocytochemical studies. Peptides 3:291-298.

Bras H, Cavallari P, Jankowska E, McCrea D (1989) Comparison of effects of monoamines on transmission in spinal pathways from group I and II muscle afferents in the cat. Exp Brain Res 76:27-37.

Cameron AA, Khan IA, Westlund KN, Willis WD (1995) The efferent projections of the periaqueductal gray in the rat: a Phaseolus vulgarisleucoagglutinin study. II. Descending projections. J Comp Neurol 351:585-601.

Carstens E, Fraunhoffer M, Zimmermann M (1981) Serotonergic mediation of descending inhibition from midbrain periaqueductal gray, but not reticular formation, or spinal nociceptive transmission in the cat. Pain 10:149-167.

Coote JH, Macleod VH, Fleetwood WS, Gilbey MP (1981) The response of individual sympathetic preganglionic neurones to microelectrophoretically applied endogenous monoamines. Brain Res 215:135-145.
Dahlstrom A, Fuxe K (1964) Evidence for the existence of monoaminecontaining neurons in the central nervous system. I. Demonstration of monoamine in the cell bodies of brain stem neurons. Acta Physiol Scand 232[Suppl]:1-36.

Depaulis A, Bandler R (1991) The midbrain periaqueductal gray matter. New York: Plenum.

Duggan AW (1992) Neuropharmacology of pain. Curr Opin Neurol Neurosurg 5:503-507.

el Yassir N, Fleetwood-Walker SM, Mitchell R (1988) Heterogeneous effects of serotonin in the dorsal horn of rat: the involvement of 5-HT1 receptor subtypes. Brain Res 456:147-158.

Gao KM, Li P (1993) Post-synaptic activity evoked in the rostral ventrolateral medullary neurones by stimulation of the defense areas of hypothalamus and midbrain in the rat. Neurosci Lett 161:153-156.

Hilton SM, Smith PR (1984) Ventral medullary neurones excited from the hypothalamic and mid-brain defense areas. J Auton Nerv Syst 11:35-42.

Huangfu D, Hwang LJ, Riley TA, Guyenet PG (1994) Role of serotonin and catecholamines in sympathetic responses evoked by stimulation of rostral medulla. Am J Physiol 266:R338-352.

Inokuchi H, Yoshimura M, Polosa C, Nishi S (1990) The effects of 5-hydroxytryptamine on cat sympathetic preganglionic neurons in vitro. Kurume Med J 37:309-312.

Inui K, Murase S, Nosaka S (1994) Facilitation of the arterial baroreflex by the ventrolateral part of the midbrain periaqueductal grey matter in rats. J Physiol (Lond) 477:89-101.

Inui K, Nomura J, Murase S, Nosaka S (1995) Facilitation of the arterial baroreflex by the preoptic area in anaesthetized rats. J Physiol (Lond) 488:521-531.

Izzo PN, Jordan D, Ramage AG (1988) Anatomical and physiological evidence supporting the involvement of serotonin in the central control of cardiac vagal motoneurones in the anesthetized cat. J Physiol (Lond) 406:19P.

Izzo PN, Deuchars J, Spyer KM (1993) Localization of cardiac vagal preganglionic motoneurones in the rat: immunocytochemical evidence of synaptic inputs containing 5-hydroxytryptamine. J Comp Neurol 327:572-583.

Jensen I, Llewellyn SI, Pilowsky P, Minson JB, Chalmers J (1995) Serotonin inputs to rabbit sympathetic preganglionic neurons projecting to the superior cervical ganglion or adrenal medulla. J Comp Neurol 353:427-438.

Kadzielawa K (1983) Antagonism of the excitatory effects of 5-hydroxytryptamine on sympathetic preganglionic neurones and neurones activated by visceral afferents. Neuropharmacology 22:19-27.

Kandel ER, Schwartz JH, Jessell TM (1991) Principles of neural science. Norwalk, CT: Appleton and Lange.

Lakos S, Basbaum AI (1988) An ultrastructural study of the projections from the midbrain periaqueductal gray to spinally projecting, serotoninimmunoreactive neurons of the medullary nucleus raphe magnus in the rat. Brain Res 443:383-388.

Leung CG, Mason P (1995) Effects of anesthetic depth on the activity of pontomedullary raphe and medial reticular neurons in the rat. Brain Res 699:71-82.

Li YQ, Shinonaga Y, Takada M, Mizuno N (1993) Demonstration of axon terminals of projection fibers from the periaqueductal gray onto neurons in the nucleus raphe magnus which send their axons to the trigeminal sensory nuclei. Brain Res 608:138-140.

Lovick TA (1991) Interactions between descending pathways from the dorsal and ventrolateral periaqueductal gray matter in the rat. In: The midbrain periaqueductal gray matter (Depaulis A, Bandler R, eds), pp 101-20. New York: Plenum.

Mason P (1997) Physiological identification of pontomedullary serotonergic neurons in the rat. J Neurophysiol 77:1087-1098.

Mason P, Fields HL (1989) Axonal trajectories and terminations of onand off-cells in the cat lower brainstem. J Comp Neurol 288:185-207.

Mason P, Strassman A, Maciewicz R (1988) Serotonin immunocytochemistry of physiologically characterized raphe magnus neurons. Exp Brain Res 73:1-7.

McCall RB (1984) Evidence for a serotonergically mediated sympathoexcitatory response to stimulation of medullary raphe nuclei. Brain Res 311:131-139.

Murase K, Randic M, Shirasaki T, Nakagawa T, Akaike N (1990) Serotonin suppresses $N$-methyl-D-aspartate responses in acutely isolated spinal dorsal horn neurons of the rat. Brain Res 525:84-91. 
Oliveras JL, Bourgoin S, Hery F, Besson JM, Hamon M (1977) The topographical distribution of serotoninergic terminals in the spinal cord of the cat: biochemical mapping by the combined use of microdissection and microassay procedures. Brain Res 138:393-406.

Paul D, Phillips AG (1986) Selective effects of pirenperone on analgesia produced by morphine or electrical stimulation at sites in the nucleus raphe magnus and periaqueductal gray. Psychopharmacology (Berlin) 88:172-176.

Peng YB, Lin Q, Willis WD (1996) The role of 5-HT3 receptors in periaqueductal gray-induced inhibition of nociceptive dorsal horn neurons in rats. J Pharmacol Exp Ther 276:116-124.

Potrebic SB, Fields HL, Mason P (1994) Serotonin immunoreactivity is contained in one physiological cell class in the rat rostral ventromedial medulla. J Neurosci 14:1655-1665.

Poulat P, Marlier L, Rajaofetra N, Privat A (1992) 5-Hydroxytryptamine, substance $\mathrm{P}$ and thyrotropin-releasing hormone synapses in the intermediolateral cell column of the rat thoracic spinal cord. Neurosci Lett 136:19-22.

Ranck JJ (1975) Which elements are excited in electrical stimulation of mammalian central nervous system: a review. Brain Res 98:417-440.

Rivot JP, Calvino B, Besson JM (1987) Is there a serotonergic tonic descending inhibition on the responses of dorsal horn convergent neurons to C-fibre inputs? Brain Res 403:142-146.

Sandkuhler J, Gebhart GF (1984) Relative contributions of the nucleus raphe magnus and adjacent medullary reticular formation to the inhibition by stimulation in the periaqueductal gray of a spinal nociceptive reflex in the pentobarbital-anesthetized rat. Brain Res 305:77-87.

Schenberg LC, Lovick TA (1995) Attenuation of the midbrain-evoked defense reaction by selective stimulation of medullary raphe neurons in rats. Am J Physiol 269:R1378-1389.
Shah Y, Dostrovsky JO (1980) Electrophysiological evidence for a projection of the periaqueductal gray matter to nucleus raphe magnus in cat and rat. Brain Res 193:534-538.

Urban MO, Smith DJ (1994) Nuclei within the rostral ventromedial medulla mediating morphine antinociception from the periaqueductal gray. Brain Res 652:9-16.

van Praag H, Frenk H (1990) The role of glutamate in opiate descending inhibition of nociceptive spinal reflexes. Brain Res 524:101-105.

Vanegas H, Barbaro NM, Fields HL (1984) Midbrain stimulation inhibits tail-flick only at currents sufficient to excite rostral medullary neurons. Brain Res 321:127-133.

Wiklund L, Behzadi G, Kalen P, Headley PM, Nicolopoulos LS, Parsons CG, West DC (1988) Autoradiographic and electrophysiological evidence for excitatory amino acid transmission in the periaqueductal gray projection to nucleus raphe magnus in the rat. Neurosci Lett 93:158-163.

Yaksh TL, DuChateau JC, Rudy TA (1976) Antagonism by methysergide and cinanserin of the antinociceptive action of morphine administered into the periaqueductal gray. Brain Res 104:367-372.

Yezierski RP, Wilcox TK, Willis WD (1982) The effects of serotonin antagonists on the inhibition of primate spinothalamic tract cells produced by stimulation in nucleus raphe magnus or periaqueductal gray. J Pharmacol Exp Ther 220:266-277.

Yoshimura M, Nishi S (1982) Intracellular recordings from lateral horn cells of the spinal cord in vitro. J Auton Nerv Syst 6:5-11.

Zagon A, Smith AD (1993) Monosynaptic projections from the rostral ventrolateral medulla oblongata to identified sympathetic preganglionic neurons. Neuroscience 54:729-743. 